\title{
Identification of novel components of Trypanosoma brucei editosomes
}

\author{
ASWINI K. PANIGRAHI, ${ }^{1,2}$ ACHIM SCHNAUFER, ${ }^{1,2}$ NANCY L. ERNST, ${ }^{1,2}$ BINGBING WANG, ${ }^{1,2}$ \\ NICOLE CARMEAN, ${ }^{1}$ REZA SALAVATI, ${ }^{1,2}$ and KENNETH STUART ${ }^{\mathbf{1 , 2}}$ \\ ${ }^{1}$ Seattle Biomedical Research Institute, Seattle, Washington 98109, USA \\ ${ }^{2}$ Department of Pathobiology, University of Washington, Seattle, Washington 98195, USA
}

\begin{abstract}
The editosome is a multiprotein complex that catalyzes the insertion and deletion of uridylates that occurs during RNA editing in trypanosomatids. We report the identification of nine novel editosome proteins in Trypanosoma brucei. They were identified by mass spectrometric analysis of functional editosomes that were purified by serial ion exchange/gel permeation chromatography, immunoaffinity chromatography specific to the TbMP63 editosome protein, or tandem affinity purification based on a tagged RNA editing ligase. The newly identified proteins have ribonuclease and/or RNA binding motifs suggesting nuclease function for at least some of these. Five of the proteins are interrelated, as are two others, and one is related to four previously identified editosome proteins. The implications of these findings are discussed.
\end{abstract}

Keywords: RNA editing; protein; mass spectrometry; chromatography; TAP-tag; ribonuclease

\section{INTRODUCTION}

Uridylate (U) insertion/deletion editing, which appears to be unique to trypanosomatids, processes most mitochondrial pre-mRNAs to produce mature mRNAs (see Kable et al. 1997; Estevez and Simpson 1999; Stuart et al. 2000; Madison-Antenucci et al. 2002; Stuart and Panigrahi 2002). The editing process is performed by the editosome, a multiprotein complex, which catalyzes the series of coordinated enzymatic steps that result in edited RNA. Small ( $\sim 60 \mathrm{nt})$ mitochondrial guide RNAs (gRNAs) specify the sites of editing and the number of $U$ insertions and deletions. The first enzymatic step in the editing process is gRNA-directed endonucleolytic cleavage of the pre-mRNA at the editing site. Subsequently, U's are added to the $3^{\prime}$ terminus of the 5' cleavage product by 3' Terminal Uridylyl Transferase (TUTase) for insertion or are removed by $3^{\prime}$ exo-uridylase (exo-Uase) for deletion. The $U$ addition or deletion step is followed by ligation of $5^{\prime}$ and $3^{\prime}$ cleavage fragments by RNA ligase. Each gRNA contains sequence information for the editing of multiple sites within a block of 25-35 nt in the mRNA. Most mRNAs require multiple gRNAs to direct the editing of multiple blocks to fully edit the mRNA.

Reprint requests to: Kenneth Stuart, Seattle Biomedical Research Institute, 4 Nickerson Street, Seattle, WA 98109, USA; e-mail: kstuart@ u.washington.edu.

Article and publication are at http://www.rnajournal.org/cgi/doi/ 10.1261/rna.2194603.
There has been recent progress in characterizing the editosome. The association of editing with a complex was implied by the findings that activities expected for editing sediment at 20-40S as do gRNAs and pre-mRNAs (Pollard et al. 1992; Corell et al. 1996) and two RNA ligases that were identified by adenylation and deadenylation (Sabatini and Hajduk 1995). SDS-PAGE analysis of editosomes purified by various biochemical methods revealed between 7 and more than 20 major protein bands depending on the procedure (Rusché et al. 1997; Madison-Antenucci et al. 1998; Panigrahi et al. 2001a). The genes for the two RNA Editing Ligases (REL) 1 and 2, formerly TbMP52 and TbMP48, respectively, were identified by mass spectrometry of the purified proteins (Panigrahi et al. 2001a) and shown to encode RNA ligases (McManus et al. 2001; Rusché et al. 2001; Schnaufer et al. 2001) and correspond to bands IV and V (Rusché et al. 1997). TbREL1 was shown by gene inactivation studies to be essential for editing and for viability of the parasite (Schnaufer et al. 2001) and similar studies indicated that TbREL2 is not essential for editing or cell survival (Drozdz et al. 2002). Genes for four other editosome proteins, TbMP18, TbMP42, TbMP63, and TbMP81, were also identified by mass spectrometry of purified editosomes (Panigrahi et al. 2001b). These proteins share sequence conservation among themselves to a certain extent and the largest three have zinc fingers. The two largest of these proteins are essential for editing, as inactivation 
of expression of the TbMP63 (band III; Huang et al. 2002) or TbMP81 (Drozdz et al. 2002) gene block editing and result in the loss of the TbREL1 and TbREL2, respectively. A DEAD box helicase, mHEL61p, has a role in editing, as null mutants of Trypanosoma brucei have reduced edited mRNAs in vivo (Missel et al. 1997). A mitochondrial 3' TUTase gene was also found to be essential for editing in $T$. brucei by inhibition of its expression (Aphasizhev et al. 2002).

In addition, several RNA-binding proteins, gBP21 (Koller et al. 1997) and the related gBP25 (Blom et al. 2001), as well as REAP1 (Madison-Antenucci et al. 1998), TBRGG1 (Vanhamme et al. 1998), and RBP16 (Hayman and Read 1999), may have roles in RNA editing. At present, it is unclear if or to what extent these proteins are associated with the editosome. The roles of these proteins may be in gRNA processing, annealing of gRNA and mRNA (Muller et al. 2001), and/or transport of RNAs to the editosome (Madison-Antenucci and Hajduk 2001).

This study describes the identification of nine additional editosome proteins, all of which are stably associated with the $\sim 20$ S editosome. These proteins are novel but have sequence characteristics suggesting roles in RNA interaction and processing. The editosome proteins identified to date have varying degrees of sequence similarities, which reveal that they occur as pairs and sets of related proteins.

\section{RESULTS}

Editosomes were purified by three different approaches to determine their protein content. They were purified from mitochondrial lysates by sequential column chromatography as previously described (Panigrahi et al. 2001a), from glycerol gradient-fractionated mitochondrial lysates by affinity purification using a MAb specific for editosome protein TbMP63 (Panigrahi et al. 2001b), and from total cell lysates of transgenic trypanosomes by the tandem affinity purification (TAP) procedure (Rigaut et al. 1999). Trypanosomes that express TbREL1 with a C-terminal TAPtag under the control of a tetracyclineinducible promoter were prepared as described in Materials and Methods. The TAP-tagged protein was efficiently expressed in vivo and glycerol gradient analysis showed incorporation into $\sim 20$ S complexes (results not shown).
The TAP-tagged complexes underwent a first affinity chromatography with an IgG column, which binds the protein A segment of the TAP-tag, and were eluted by cleavage with TEV protease. They then underwent a second affinity chromatography with a calmodulin column, which binds the calmodulin-binding protein (CBP) segment of the TAP-tag, and were eluted using EGTA. Editosomes purified by these three methods all contained the four proteins for which we have MAbs, TbMP81, TbMP63, TbREL1 (TAP-tagged in one case), and TbMP42, as shown by Western analysis (Fig. 1A), and a fifth protein TbREL2, along with TbREL1, was identified by adenylation (Fig. 1B). The editosomes purified by these three methods were all functional in full round in vitro deletion editing (Fig. 1C). Hence, all three methods resulted in functional editosomes.

The proteins in the purified editosomes and their corresponding genes were identified by a combination of liquid chromatography tandem mass spectrometry (LC-MS/MS) and DNA sequence database analysis as described
A

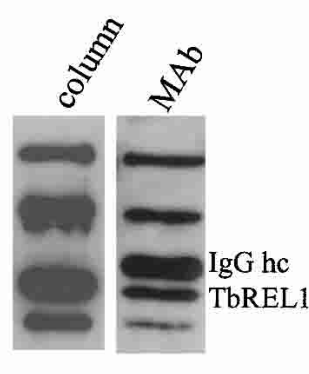

B

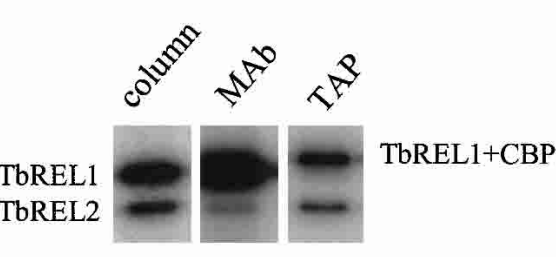

C

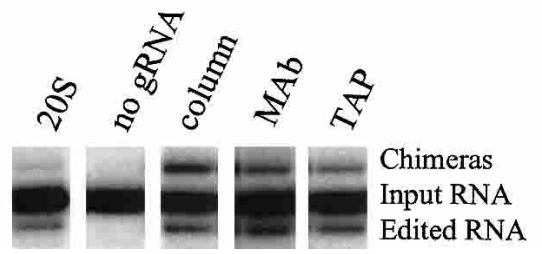

D
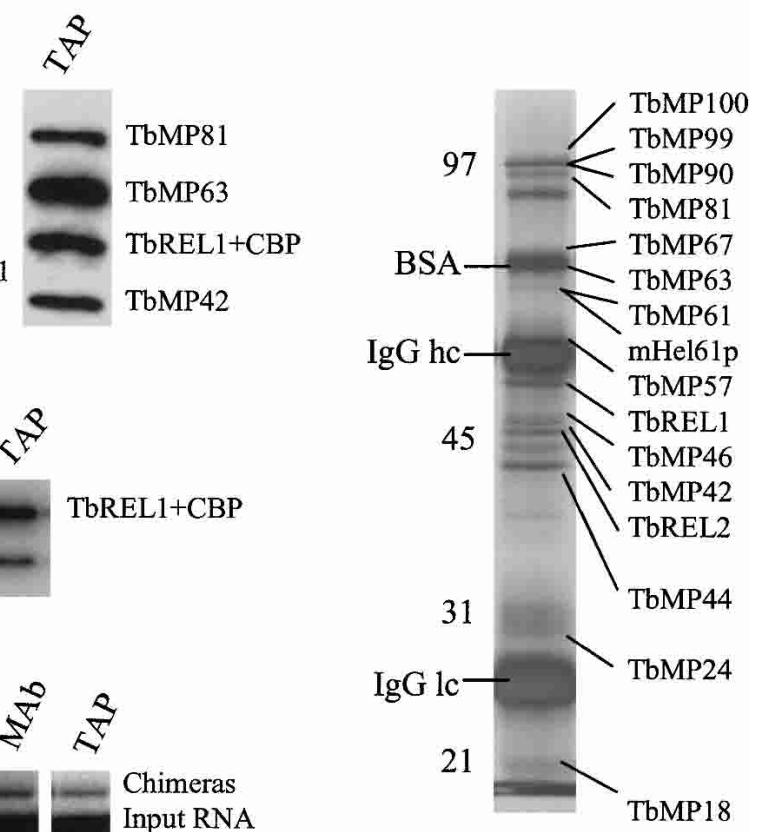

FIGURE 1. Isolation of T. brucei editosomes. (A) Western analysis of the complexes purified by column chromatography (sequential ion-exchange and gel filtration), MAb affinity, and the TAP method showing the presence of editosome proteins TbMP81, TbMP63, TbREL1, and TbMP42. IgG heavy chain (hc) and tagged TbREL1 are indicated. (B) Adenylation of editosome preparations. The adenylated TbREL1, TbREL2, and tagged TbREL1 are indicated. $(C)$ In vitro deletion RNA editing assays using the purified editosomes. Mitochondrial 20S fraction served as a positive control; no gRNA indicates the negative control. Input pre-mRNA, resulting edited RNA, and chimeras resulting from ligation of cleaved $3^{\prime}$ pre-mRNA to gRNA are indicated. $(D)$ Silver-stained SDS-PAGE protein profile of MAb affinity-purified complexes. Proteins identified by LC-MS/MS are indicated, although some were not identified as discussed in the text. Size standards, bovine serum albumin (BSA) used as a blocking agent, and IgG heavy (hc) and light (lc) chains of the MAb are indicated. The relative migration of some proteins differs from that predicted from the gene sequence and some proteins comigrate. 
(Panigrahi et al. 2001b). The editosome proteins were des-

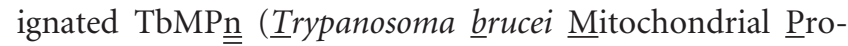
tein with $\underline{\underline{n}}$ indicating the preprocessed molecular weight of the protein predicted by the open reading frame) and the corresponding genes as TbMPn according to the previous convention (Clayton et al. 1998; Panigrahi et al. 2001a). Analysis of protein bands from MAb affinity-purified editosomes identified 16 proteins (Fig. 1D). A representative collision-induced dissociation (CID) spectrum that was obtained from the mass spectrometer from tryptic peptide VLDLEEVYFR is shown in Figure 2A. This peptide corresponds to position $583-592$ on a $90 \mathrm{kD}$ protein predicted by T. brucei ORF CHR1.148 (accession no. CAB95444). Thirteen other tryptic peptides were identified that cover $16.8 \%$ of the amino acids in this protein (Fig. 2B). We designated this protein TbMP90. Similarly, TbMP100 (DNA clones 20G11, 32N6-TIGR), TbMP99 (ORF TRYP10.0.000037_106-Sanger), TbMP67 (ORF TRYP10.0.000155_38-Sanger), TbMP61 (ORF
TRYP10.0.000155_52-Sanger), TbMP57 (DNA clones 8B08, 105B11, 9C14-TIGR), TbMP46 (DNA clone 28E9-TIGR), TbMP44 (ORF TRYP11.0.000049_1-Sanger), and TbMP24 (ORF TRYP10.0.000155_8-Sanger) were identified by identification of multiple tryptic peptides. Sequence analysis of the TbMP24 and TbMP99 cDNA clones showed that the second and third AUGs are used as the start codons, respectively. As summarized in Table 1, six editosome proteins that we previously identified by LC-MS/MS, TbREL1, TbREL2, TbMP81, TbMP63, TbMP42, TbMP18 (Panigrahi et al. 2001a, 2001b) and the DEAD box protein mHel61p (Missel et al. 1997), were also identified in purified editosomes by multiple peptide matches. Editosomes purified by the three different methods had similar but not identical protein profiles. Of the 16 proteins detected in MAb affinity-purified complexes, two were not detected in editosomes purified by sequential column chromatography and five were not detected in TAP-tag purified editosomes

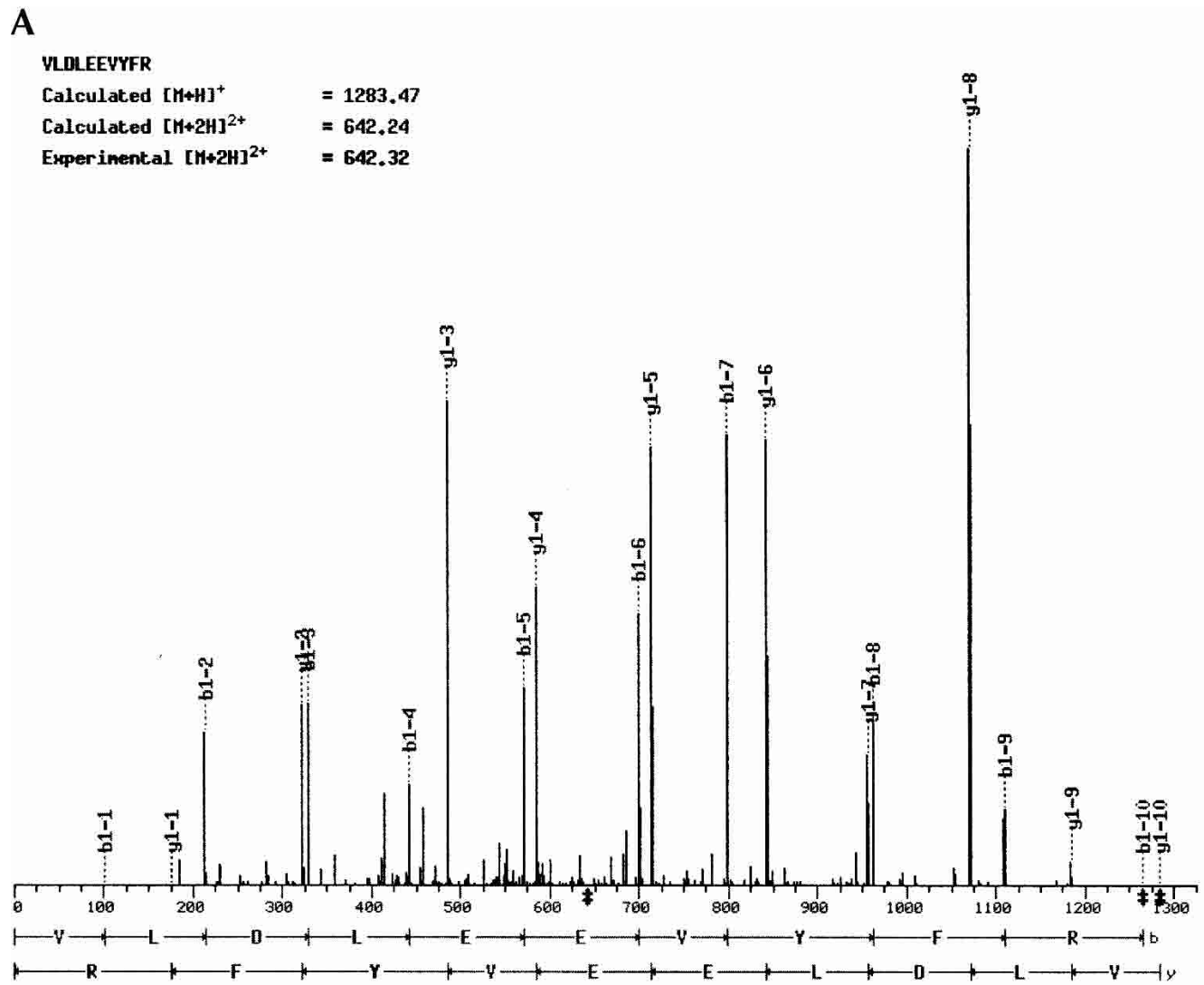

B

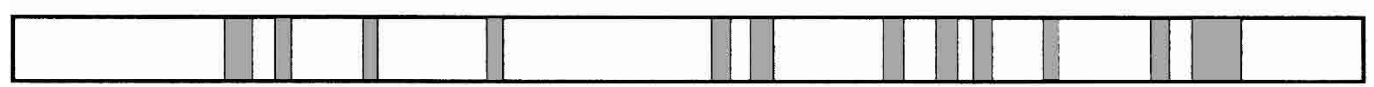

FIGURE 2. Identification of editosome protein TbMP90 by LC-MS/MS analysis. (A) CID spectrum of a tryptic peptide generated by the mass spectrometer. The spectrum matches that predicted for the peptide VLDLEEVYFR, both from $\mathrm{N}$ to $\mathrm{C}$ terminus ( $\mathrm{b}$ ions) and $\mathrm{C}$ to $\mathrm{N}$ terminus ( $\mathrm{y}$ ions), and corresponds to a peptide predicted from the CHR1.148 (TbMP90) gene sequence. (B) Fourteen tryptic peptides (shaded region, peptide 7 and 8 from left overlap) were identified across the protein that covered $16.8 \%$ of the sequence. 
TABLE 1. Proteins identified in editosomes isolated by MAb affinity, column chromatography, and TAP-tag procedures

\begin{tabular}{lccc}
\hline Protein & MAb affinity & Column & TAP-tag \\
\hline TbMP100 & $\mathrm{X}$ & $\mathrm{X}$ & \\
TbMP99 $^{\mathrm{a}}$ & $\mathrm{X}$ & $\mathrm{X}$ & $\mathrm{X}$ \\
TbMP90 $^{\mathrm{a}}$ & $\mathrm{X}$ & $\mathrm{X}$ & \\
TbMP81 & $\mathrm{X}$ & $\mathrm{X}$ & $\mathrm{X}$ \\
TbMP67 & $\mathrm{X}$ & $\mathrm{X}$ & $\mathrm{X}$ \\
TbMP63 & $\mathrm{X}$ & & $\mathrm{X}$ \\
TbMP61 & $\mathrm{X}$ & $\mathrm{X}$ & \\
mHel61p $_{\text {TbMP57 }}^{\mathrm{a}}$ & $\mathrm{X}$ & $\mathrm{X}$ & $\mathrm{X}$ \\
TbREL1 & $\mathrm{X}$ & $\mathrm{X}$ & $\mathrm{X}$ \\
TbREL2 & $\mathrm{X}$ & $\mathrm{X}$ & $\mathrm{X}$ \\
TbMP46 & $\mathrm{X}$ & $\mathrm{X}$ & $\mathrm{X}$ \\
TbMP44 & $\mathrm{X}$ & $\mathrm{X}$ & $\mathrm{X}$ \\
TbMP42 & $\mathrm{X}$ & $\mathrm{X}$ & $\mathrm{X}$ \\
TbMP24 & $\mathrm{X}$ & $\mathrm{X}$ & \\
TbMP18 & $\mathrm{X}$ & & \\
\hline
\end{tabular}

adentified in this study

(Table 1). Other editosome proteins that correspond to genes whose sequences are not yet in the T. brucei DNA sequence database may be identified from the LC-MS/MS data.

Previous studies showed that the two RNA editing ligase proteins TbREL1 and TbREL2 are related to each other (Panigrahi et al. 2001a; Schnaufer et al. 2001). Four other proteins (TbMP81, TbMP61, TbMP42, and TbMP18) were also shown to have varying degree of sequence similarity and domain conservation among them (Panigrahi et al. 2001b). The editosome protein TbMP24 identified here is related to these four proteins, with the greatest sequence similarity to TbMP42 (29\% sequence identity and $42 \%$ similarity over 109 amino acids). Similarly, pairwise amino acid sequence comparison and homology searches showed that another set of five proteins, TbMP90, TbMP67, TbMP61, TbMP46, and TbMP44, have some sequence similarity and domain conservation among them (Table 2; Fig. 3A). Of these proteins TbMP90, TbMP67, and TbMP61 are more closely related to each other, as are TbMP46 and TbMP44 (Table 2). Three-way sequence alignment showed the mid region is partially conserved among TbMP90, TbMP67 and TbMP61 (Fig. 3B). Similarly, the mid region of TbMP46 and TbMP44 is partially conserved (Fig. 3C).

Proteins TbMP100 and TbMP99 are similar to each other (overall 28.5/45.8\% identity/similarity), and they have a highly conserved C-terminal one-third region (40/61\% identity/similarity; Fig. 4). Another novel protein, TbMP57, was identified in editosomes prepared by all three different methods. This protein has sequence similarity to a $108-\mathrm{kD}$ protein $3^{\prime}$ TUTase that was cloned from T. brucei (Aphasizhev et al. 2002).

The functions of some editosome proteins have been determined whereas the functions of others are suggested by the motifs that they contain (Table 3). TbREL1 and TbREL2 proteins have significant sequence homology to ligase domains and catalyze RNA ligation (McManus et al. 2001; Rusché et al. 2001; Schnaufer et al. 2001). The TbMP81, TbMP63, and TbMP42 proteins contain C2H2 zinc finger motifs (Panigrahi et al. 2001b), implying molecular interaction. The other two proteins in this related set, TbMP24 and TbMP18, contain RNA-binding domains. Thus, this group of five proteins is likely to be involved in proteinprotein and/or protein-RNA interactions. Indeed, it has been shown that TbMP63 interacts with TbREL1 (Panigrahi et al. 2001b) and TbMP81 with TbREL2 in vitro (S.S. Palazzo, unpubl.).

The TbMP61 protein has a ribonuclease III motif (amino acids 187-309) located within the sequence that is most conserved with its related proteins TbMP90 and TbMP67. The catalytic center, key residues $\mathrm{E}$ and $\mathrm{G}$ that function in substrate binding and $\mathrm{Mg}$ enhancement of catalysis, respectively, in Escherichia coli (Mian 1997) and flanking sequences are conserved (Fig. 3B). Hence, TbMP61, TbMP90, and TbMP67 may function as nucleases. The TbMP44 protein also contains a ribonuclease III-like motif within this region whereas TbMP46 does not, but contains a potential Pumilio family RNA-binding domain motif (amino acids 263-300; Fig. 3C). TbMP44 has been shown to be essential

TABLE 2. Pairwise sequence comparison between editosome proteins

\begin{tabular}{|c|c|c|c|c|c|c|c|}
\hline & \multirow[b]{2}{*}{ Protein } & \multicolumn{5}{|c|}{ Protein } & \\
\hline & & TbMP90 & TbMP67 & TbMP61 & TbMP46 & TbMP44 & \\
\hline \multirow{5}{*}{ 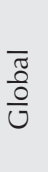 } & TbMP90 817 аa & & $32 / 46(214)$ & $27 / 42(332)$ & - & - & \\
\hline & TbMP67 596 aа & $17.2 / 28.6$ & & $36 / 52(287)$ & $22 / 46(118)$ & $21 / 44(198)$ & $\bar{\sigma}$ \\
\hline & TbMP61 538 aа & $17.9 / 26.8$ & $23 / 34$ & & $22 / 37(275)$ & - & ర్ర \\
\hline & TbMP46 414 aa & $11.3 / 17.8$ & $13.5 / 23.3$ & $17.7 / 28.6$ & & $28 / 45(260)$ & 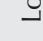 \\
\hline & TbMP44 382 аа & $10.7 / 18.8$ & $12.8 / 24.1$ & $13.5 / 22.6$ & $21.9 / 37.8$ & & \\
\hline
\end{tabular}

The global alignment covers the whole length of both sequences and the local alignment covers the region of greatest similarity. The numbers represent percent identity over percent similarity and the length of the region is indicated in parentheses.

aa $=$ amino acids. 


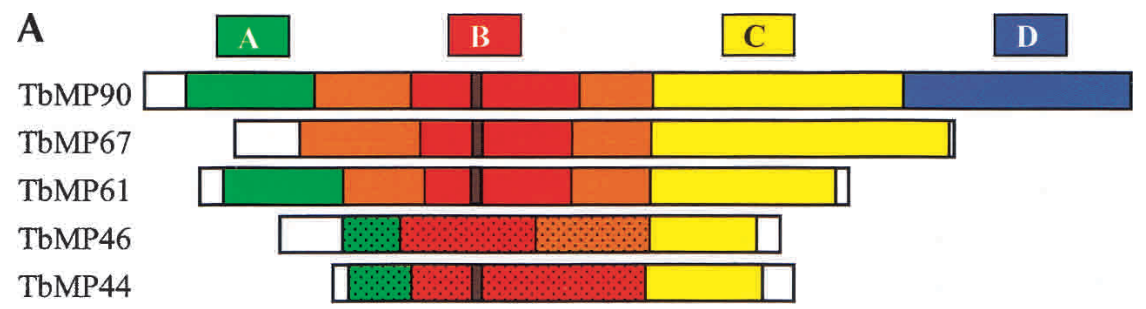

\section{B}

TbMP61 IAKMWWHRLNTSP--- - -AFNRIPKLSHD--NSHTRKRRLQYLLKFLKDRDVIRDTFNVHN- - - SSGTAG-- - -RSWEFERLEWIGDNVVKYVFNDRFNVIFPV TbMP 67 LVGTWWSRLNDTKREPALDYKRIPSLSAS - -TTKKRLWRMRFLLQYLRDRGI IRYSLTPAK-- - VAGAGDNAFVRSARFERSEMIGDNIVKVVVPDRLVRLFPA TbMP 90 VYFVWADTLYQSS-----VFQR I PELVSPRWTVDKRSEVLAKILFMLKDMGVIDISLAAQAPDLFDNTAQQVHHRRRVAFERLEY IGDNSWGNHLSNRMMLLFPD

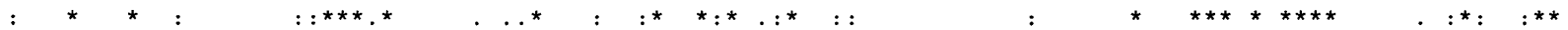

R---EGGIRGRLGYAQFMIDGNDGLARAYDYLELQKLTLS- - -DRVVSKFKSDVVETLFGELQLYIWSSETDAG-TTCYPLPFTGEMFSLRALVWHVMEELAHVMFMYHVE D-- -EGGVTYKLASIQQLLDSNEGLLE IYDYLGLNNI IGV--- -RLPNNKTKSDVVEALFGELQTFLWASELSCG-SCQYPAFPTAEHRYVRALVDHLLNELTHMVIMWRVE RQWTYSQNAYTFNCFRDACEMNVTLEFMFDTLRVGELLPPGVREKLGTGKIKADVVEAVIGELHVTLWGLEPQLYDSVCFVEINGVGEARLAALVQHCLTEIYDLIVLSYVQ

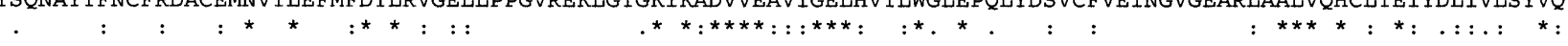

C

TBMP46 CLLCDVSYESWGDHAESTTHIARHAICRTFVSPERHNAVMQQLWKHIRLDFGYVDEVTHKKEDRRRMRLASTMRHLQEKGVLHHSLPRVTVDAQSEVSLT

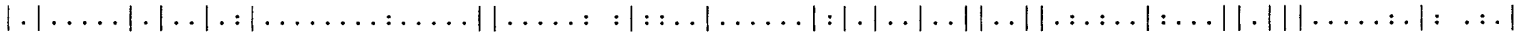

TbMP44 CALTGKCVEDWESHRKSFDMRIFELLKGRLTSPTEPLPI - KQIYATIANPCRLVEEFTCAKTTRRLGRLHTALSFLRRHNVLLHSLLFHVKETQT-WNTT

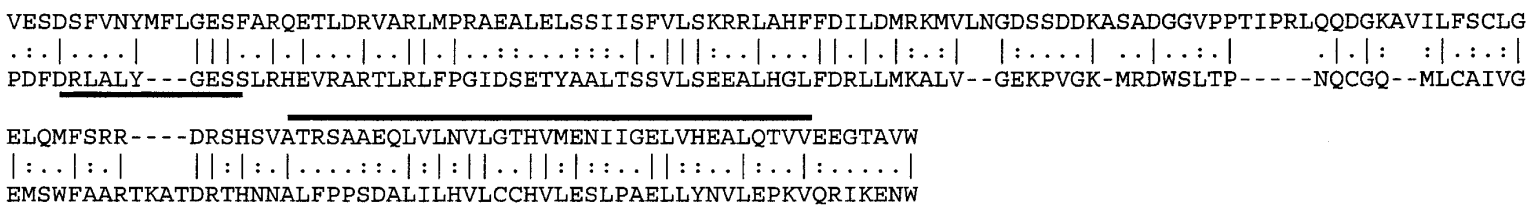

FIGURE 3. Sequence similarities among TbMP90, TbMP67, TbMP61, TbMP46, and TbMP44. (A) Diagram showing a conserved mid-region (red), and weakly similar $\mathrm{N}$ (green) and $\mathrm{C}$ terminus (yellow) of these proteins. TbMP90 has a unique C terminus (blue). The putative catalytic center of the RNase III motif is indicated in black. The upstream and downstream sequence of this motif is similar between most of the proteins (orange). TbMP46 and TbMP44 have greater sequence conservation among them (dotted) than to the other three proteins. (B) Sequence conservation the in mid-region of TbMP61 (amino acids 162-355), TbMP67 (amino acids 123-325) and TbMP90 (amino acids 196-407). The amino acid alignments indicate conserved $\left({ }^{*}\right)$, semiconserved (:), and partially conserved (.) amino acids among these proteins. A line indicates the predicted catalytic RNase III domain, and it is related to the consensus pattern [DEQ]-[KRQT]-[LM]-E-[FYW]-[LV]-G-D-[SARH]. (C) Amino acids sequence similarities [conserved (|), semiconserved (:), and partially conserved (.)] of TbMP46 (amino acids 51-306) and TbMP44 (amino acids 14-258), and likely domains therein (indicated by a line). TbMP46 contains a probable Pumilio-family RNA binding domain (one repeat unit), and TbMP44 a RNase III domain.

for RNA editing and for the structural integrity of the editosome (B. Wang, in prep.).

The TbMP100 and TbMP99 proteins have endonuclease/ exonuclease/phosphatase family motifs (pfam03372, probability 2 e-10, and 3 e-10, respectively) suggesting that they may be nucleases. This motif is located in the C-terminal one-third region that is highly conserved between them (Fig. 4). The TbMP57 protein has poly(A) polymerase and nucleotidyl transferase motifs and, as will be described in detail elsewhere, has TUTase activity (N.L. Ernst, unpubl.).

\section{DISCUSSION}

This study identified nine additional novel protein components of $T$. brucei editosomes. These proteins along with seven previously identified editosome proteins comprise much, but perhaps not all, of the mass of the stable catalytic core of the editosome. Five of the proteins are interrelated, and another protein is related to four previously identified editosome proteins, making another set of five related proteins. Another two of the newly identified proteins are also related to each other. In addition, another protein is related to a TUTase that is essential for editing. Most of the proteins have motifs suggesting roles in molecular interaction, especially with nucleic acids, and/or nuclease or TUTase activity.

Several criteria indicate that the 16 identified proteins are components of the editosome. The proteins were detected by LC-MS/MS analysis of editosomes isolated with high stringency (salt and nonionic detergent) during MAb affinity isolations, indicating that most of these proteins are in the stable core of the editosome. Fifteen proteins were identified in the editosomes that were isolated by at least two independent purification methods, showing stable associa- 


\section{TbMP100 KLLTWNVMFDRYSGKPTPLGMPGIDWCSPKRYPVIAKI IEEEDADVVGMEVEPVFWEFLSKRALIRQRYYFSCGHMSPAIAPWGVLMLIHRRRLPVQS $:::|||| \cdot||:||:. .|||| \ldots|||||: \ldots||\ldots:|: \ldots:|\ldots||||:||||||.: .::||:: \ldots:|::|\ldots:| \ldots||.||||.|::|:|||||\cdot| . \mid$ \\ TbMPو9 RVVTWNVQFSRHSGERTPLGRDGIDWCTSTRYVALAQTLEGLDADVIGMEVEPAWCKYLSQQPWVREKYAMTCCEHSHAIQPWGVMLLV-RRSLCVTS

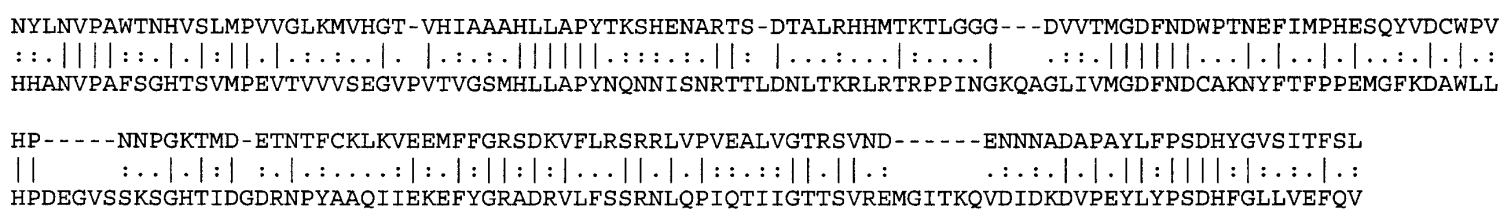

FIGURE 4. Sequence similarities [conserved (|), semiconserved (:), and partially conserved (.)] of the C termini of TbMP100 (amino acids 619-891) and TbMP99 (amino acids 618-906) that belong to the endonuclease/exonuclease/phosphatase family of proteins.

tion with the complex. The differential composition of the editosomes isolated by different methods may be due to protein dissociation during the chromatography and the effect of the tag on associations of some of the proteins with the complex. TbMP67 was only detected in MAb affinityisolated editosomes, but its sequence similarity to other editosome proteins suggests that it is an editosome component. Studies in progress indicate interactions among many of these proteins (A. Schnaufer, N.L. Ernst, and S.S. Palazzo, unpubl.) much as TbMP63 has been shown to physically interact with TbREL1 (Panigrahi et al. 2001b). The existence of two sets of five related proteins and two sets of related pairs of proteins, including TbREL1 and TbREL2, also implies that those 14 proteins are editosome components.

The newly identified nine proteins add to the candidate proteins that perform specific functions in editing, including endonuclease, exo-Uase, and TUTase activities. TbREL1 and TbREL2, which were previously identified (Panigrahi et al. 2001a), catalyze the RNA ligation that occurs during editing (Rusché et al. 2001; Schnaufer et al. 2001). TbMP57 identified here has TUTase activity and sequence similarity to a T. brucei $108-\mathrm{kD} 3^{\prime}$ TUTase. The $108-\mathrm{kD} 3^{\prime}$ TUTase was identified in the Simpson laboratory and inactivation of expression of this gene by RNAi blocks editing (Aphasizhev et al. 2002). However, it was not detected in isolated editosomes and most of $108-\mathrm{kD} 3^{\prime}$ TUTase sediments away from peak editing activities in glycerol gradients (Aphasizhev et al. 2002). One possibility is that the TbMP57 TUTase may add U's to pre-mRNA during editing whereas the $108-\mathrm{kD} 3^{\prime}$ TUTase may add U's to the $3^{\prime}$ end of the gRNA. Alternatively, the $108-\mathrm{kD} 3^{\prime}$ TUTase may add U's to pre-mRNA but not be tightly associated with the editosome. This may parallel the situation with mHel61p, a RNA helicase that appears to have a role in editing but is not essential based on gene knockout studies (Missel et al. 1997). However, homology searches identified several putative DEAD box proteins in the T. brucei database that appear to be homologs of mHel61p and that may play compensatory roles in vivo (Stuart and Panigrahi 2002). TbMP100 and TbMP99 are related and both have an endonuclease/exonuclease/phosphatase motif and hence are candidates for proteins that catalyze the endonuclease and/or exo-Uase activities associated with editing. Because another set of editosome proteins has probable endonuclease function as discussed below, one or both of these proteins may function as an exo-Uase during the editing cycle.

TbMP24 has a S1 domain suggesting that it may be an RNA-binding protein as appears to be the case for the other four members (TbMP81, TbMP63, TbMP42, and TbMP18) of that family (Panigrahi et al. 2001b). Of the five remaining proteins with varying degrees of sequence relatedness, TbMP90, TbMP67, TbMP61, TbMP46, and TbMP44, all except TbMP46 have a sequence related to a ribonuclease III motif. This suggests that they may have nuclease functions associated with editing. This family of proteins cleaves double-stranded RNAs (PROSITE documentation: PDOC00448; http://www.expasy.org). The first enzymatic step in the RNA editing cycle is cleavage of pre-mRNA in the double-stranded pre-mRNA-gRNA duplex; thus endonuclease function(s) would be consistent with the predicted motifs of these proteins. It is also possible that some of these proteins have retained noncatalytic functions such as RNA binding. The presence of six potential nucleases may suggest that nucleases may play roles other than the endonuclease and exoUase steps proposed for the editing mechanism (Kable et al. 1997) such as accommodation of substrate differences that are produced during the editing at multiple sites. In any event, TbMP44 is essential for editing and for editosome integrity (B. Wang, in prep.).

The editosomes that have been characterized here are the more stable complexes, which can catalyze a full round of editing in at least one site. The editosome preparation described by Rusché et al. (1997) contained seven major proteins, of which band II corresponds to TbMP81, III to TbMP63, IV to TbREL1, V to TbREL2, VI to TbMP42, VII to TbMP18 (Huang et al. 2002), and, based on apparent molecular size, I to TbMP90 or TbMP100/TbMP99. Although this preparation catalyzed insertion and deletion editing, some editosome proteins described in this article and elsewhere, including those that appear essential for editing, were not evident to the authors. These proteins include two TUTases (TbMP57 and 108-kD 3' TUTase) and TbMP44, which is essential for editing. It seems likely that such editosome proteins were present but less abundant than the seven major proteins in this preparation, and thus 
TABLE 3. Probable and demonstrated function(s) of $T$. brucei mitochondrial editosome proteins

\begin{tabular}{|c|c|c|c|}
\hline Protein $^{1}$ & Probable motifs/domains/family ${ }^{2}$ & Function/probable function ${ }^{3}$ & Reference \\
\hline TbMP81 (a) & $\mathrm{C} 2 \mathrm{H} 2 \mathrm{Zn}$ finger (PS50157) & Macromolecule interaction & $\begin{array}{l}\text { Panigrahi et al. 2001b; Drozdz et al. } \\
2002\end{array}$ \\
\hline TbMP63 (a) & $\mathrm{C} 2 \mathrm{H} 2 \mathrm{Zn}$ finger (PS50157) & Macromolecule interaction & $\begin{array}{l}\text { Panigrahi et al. 2001b; Huang et al. } \\
2002\end{array}$ \\
\hline TbMP42 (a) & $\mathrm{C} 2 \mathrm{H} 2 \mathrm{Zn}$ finger (PS50157) & Macromolecule interaction & Panigrahi et al. 2001b \\
\hline TbMP24 (a) & S1 domain (PS50126) & RNA interaction & This study \\
\hline TbMP18 (a) & Single-strand binding protein family (PF00436) & RNA interaction & Panigrahi et al. $2001 \mathrm{~b}$ \\
\hline TbMP90 (b) & Ribonuclease III (PS50142) & Nuclease & This study \\
\hline TbMP67 (b) & Ribonuclease III (PS50142) & Nuclease & This study \\
\hline TbMP61 (b) & Ribonuclease III (PS50142) & Nuclease & This study \\
\hline TbMP46 (b) & Pumilio-family RNA binding (PS50303) & Macromolecule interaction & This study \\
\hline TbMP44 (b) & Ribonuclease III (PS50142) & Structure/Nuclease & This study; B. Wang, in prep. \\
\hline TbREL1 (c) & Ligase (CDD-7281) & RNA ligase & $\begin{array}{l}\text { Panigrahi et al. 2001a; Schnaufer et al. } \\
2001\end{array}$ \\
\hline TbREL2 (c) & Ligase (CDD-7281) & RNA ligase & $\begin{array}{l}\text { Panigrahi et al. 2001a; Schnaufer et al. } \\
2001\end{array}$ \\
\hline TbMP100 (d) & Endonuclease/exonuclease/phosphatase (PF03372) & Nuclease & This study \\
\hline TbMP99 (d) & Endonuclease/exonuclease/phosphatase (PF03372) & Nuclease & This study \\
\hline TbMP57 & $\begin{array}{l}\text { PAP_core, PAP_associated, and } \\
\text { Nucleotidyltransferase domains (PS50154, } \\
\text { PS50155, PF01909) }\end{array}$ & Terminal uridylyl transferase & This study; N. Ernst unpubl. \\
\hline mHel61p & DEAD box (PF00270), Helicase_C (PF00271) & Helicase & Missel et al. 1997 \\
\hline
\end{tabular}

${ }^{1}$ Proteins that show sequence similarity between them have been grouped as a, b, c, and $\mathrm{d}$.

${ }^{2}$ PROSITE (PS), Pfam (PF), and Conserved Domain Database (CDD) accession numbers for the motifs/domains/family are given in parentheses.

${ }^{3}$ The proteins with macromolecule interaction function may be involved in RNA-protein and/or protein-protein interactions.

contributed to the editing activity observed by Rusché et al. (1997).

Some proteins with demonstrated or possible roles in editing were not found associated with the stable editosomes described here. These include the $108-\mathrm{kD}$ TUTase (Aphasizhev et al. 2002), gBP21 (Koller et al. 1997; Allen et al. 1998) and the related protein gBP25 (Blom et al. 2001), RBP16 (Hayman and Read 1999), TbRGG1 (Vanhamme et al. 1998), and REAP1 (Madison-Antenucci et al. 1998). This may reflect a low affinity and/or transient association with the editosome or roles associated with processes other than the catalytic steps of editing. Editing probably entails a dynamic series of events that affect protein association with the editosome and perhaps editosome composition (see Stuart and Panigrahi 2002). Hence, some proteins may function in editing but may not be stable components of the editosome or perhaps not even associated with the editosome. Editosomes and editing activities sediment in glycerol gradients with peaks at $\sim 20$ S and $\sim 40$ S (Pollard et al. 1992; Piller et al. 1995; Corell et al. 1996), and the relationship between these complexes is unclear. One possibility is that they represent editosomes in various stages of editing and/ or association with proteins with roles in editing.

The editing endo- and exonucleases are not yet known although several candidates have been identified in this article. There may be editing endonucleases specific for insertion versus deletion substrates, similar to the TbREL1 and TbREL2 ligases that function in deletion versus insertion editing (Cruz-Reyes et al. 2002), as well as multiple nucleases to accommodate differences in substrate sequences, gRNA interactions, and positions in the editosome that are produced during the editing of multiple sites. The presence of pairs and sets of related proteins, some with clearly related activities, suggests that insertion and deletion editing are physically and functionally separate. In addition, some essential proteins for editing that are not part of the editosome may or may not directly interact with the catalytic complex. Because editing is regulated during the life cycle of T. brucei (Schnaufer et al. 2002), other complexities are bound to be uncovered. Hence, although the steps in editing and the proteins that catalyze these steps are becoming clarified, additional complexities await elucidation.

\section{MATERIALS AND METHODS}

\section{Protein and gene identification}

Mitochondrial vesicles were isolated from T. brucei procyclic cells (strain IsTaR 1.7a) as described (Harris et al. 1990). The mitochondria were lyzed with $1 \%$ Triton $\mathrm{X}-100$ for $15 \mathrm{~min}$ at $4^{\circ} \mathrm{C}$ with bidirectional mixing, and clarified by centrifugation at 15,000 rpm for $30 \mathrm{~min}$ in a microcentrifuge. The soluble sample was fractionated on $10 \%-30 \%$ glycerol gradient, $500 \mu \mathrm{L}$ fractions were collected from the top, and the peak fractions positive for editosome as determined by Western analysis were pooled (Panigrahi et al. 2001a, 2001b). Editosomes were then immunoprecipitated from 
the pooled sample using anti-TbMP63 MAb. MAbs were incubated with anti-mouse IgG coated Immunomagnetic beads (Dynabeads M-450; DYNAL) for $1 \mathrm{~h}$, washed with IP buffer $(10 \mathrm{mM}$ Tris at $\mathrm{pH} 7.2,10 \mathrm{mM} \mathrm{MgCl}_{2}, 200 \mathrm{mM} \mathrm{KCl}, 0.1 \%$ Triton X-100), and incubated with the mitochondrial fraction. Following $1 \mathrm{~h}$ incubation at $4{ }^{\circ} \mathrm{C}$ the beads were washed four times with IP buffer. The bound samples to the beads were digested in SDSPAGE loading buffer and separated on a 10\% SDS-PAGE gel. The protein bands were visualized by silver stain. Individual bands were excised from the gel and digested with trypsin. The peptide sequences were analyzed by LC-MS/MS and T. brucei nucleotide and protein database searches (Panigrahi et al. 2001a and references cited therein). In cases where complete open reading frames (ORFs) were not available but significant peptide matches were found to genomic sequences, the proteins were identified by further reiterative database analysis and PCR amplification and sequencing of the cDNA and/or genomic DNA clones as described (Panigrahi et al. 2001b). In parallel approaches (a) the editosomes were isolated by sequential SP Sepharose, Q Sepharose, and Superose 6 column chromatography (Panigrahi et al. 2001a) and the proteins were identified by LC-MS/MS analysis of individual SDSPAGE separated protein bands, and tryptic digestion of the whole complex in solution (Panigrahi et al. 2001b) and (b) the complexes were also isolated by TAP-tag affinity approach as described below and the proteins were analyzed as above.

\section{Cloning and sequencing of the genes}

The TbMP100 ORF was amplified from T. brucei genomic DNA (strain 427) by PCR with primers 4430 (ATAAAGCTTATGGCAT TGGCTCAGTCAT) and 4331 (AATGTCGACTTACGGTAA CTTCAATGAAA; restriction sites are italicized), and cloned into pGEM-T Easy vector (Promega) and sequenced. Similarly, the TbMP99 ORF was amplified by PCR with primers 3275 (ATAG GATCCATGTTGCGCCGCAGTCGC) and 3309 (GCGGATCCG AGCTCTAAACCACCTGAAACTC), cloned, and sequenced. TbMP90 ORF was amplified by primers 4245 (GGAATTCATG CATCATCATCATCATCATTCCAACTGGTGCCACATGCG) and 4246 (TAAGCTTTCACGCACCAACCGAGATG); TbMP67 by primers 4243 (AGGTACCATGCACCATCATCATCATCATACGC GAAACCTGTCAG) and 4244 (CAAGCTTAGCAAACCTCCAAT GACG), TbMP61 by primers 4241 (AGGTACCATGCACCAT CACCATCATCATTTCAGGAGGTGGAGTAC) and 4242 (GAAG CTTAGGGAATGTAATCACTAAAC). TbMP44 ORF was amplified by PCR with primers 3324 (CGGGATCCCGATGAGAC GGGCTGTGGTAC) and 3325 (CCCAAGCTTGGGTTACCGC CCTCCCAGTGCCAG). The amplified products were cloned into pGEM-T vector and sequenced. RT-nested PCR using primer sets TSL1 (ACTAACGCTATTATTAGAACAG) and 4176 (CGAAA GAACAAACGATATG), followed by TSL2 (GAACAGTTTCTG TACTATATTG) and 4177 (TACTACTAAGTTCAAGAGCTTC) amplified the $\mathrm{N}$ terminus of TbMP46. The complete ORF sequence was obtained by assembling the sequence of the amplified product with 28E9.TJ sequence.

\section{TAP-tag purification of the editosome}

To create a vector for the inducible expression of C-terminally TAP-tagged proteins in T. brucei, the tag was amplified from plas- mid pBS1539 and inserted into plasmid pLew79, generating pLew79TAP. The TbREL1 coding sequence was released from pLew79-TbREL1 (Schnaufer et al. 2001) and inserted into pLew79TAP, yielding pLew79-TbREL1TAP. T. brucei cell line 29.13, coexpressing the TET repressor and T7 RNA polymerase was transfected with NotI-linearized pLew79-TbREL1TAP plasmid DNA. Phleomycin-resistant clones were selected and checked for tightly tetracyline-regulated expression. Expression of TbREL1TAP in the recombinant cell lines was induced for $48 \mathrm{~h}$ with tetracycline $(10 \mathrm{ng} / \mathrm{mL})$. TAP-tagged editing complexes were purified as described (Rigaut et al. 1999) from 2 L of cells harvested at a density of $\sim 20 \times 10^{6}$ cells $/ \mathrm{mL}$.

\section{In vitro assays}

Deletion editing was assayed in vitro using 3' labeled A6-U5 premRNA substrate with gA6[14] $16 \mathrm{G}$ gRNA as described (Seiwert et al. 1996). The edited products were detected by polyacrylamideurea gel electrophoresis and phosphorimaging. TbREL1 and TbREL2 were detected by auto-adenylation in the presence of $\left[\alpha-{ }^{32} \mathrm{P}\right]-\mathrm{ATP}$ as described (Sabatini and Hajduk 1995). The proteins were resolved on 10\% SDS-PAGE gels and the radiolabeled proteins were detected by PhosphorImager.

\section{Western blot analysis}

The isolated editosome fractions were digested with SDS-PAGE loading buffer and resolved on 10\% SDS-PAGE gels. The proteins were transferred onto PVDF membranes, and reacted with MAbs specific for TbMP81, TbMP63, TbREL1, and TbMP42 (Panigrahi et al. 2001a, 2001b). The filter was developed with ECL kit (Amersham) as per the manufacturer's instructions.

\section{Sequence analysis}

The predicted protein sequences were compared with the NCBI nonredundant protein database and EBI database using the BLAST algorithm. The presence of known motifs and domains in the predicted proteins were searched for in the PROSITE, InterPro, BLOCKS, and CDD databases. Homology between the proteins was determined by pairwise sequence comparison using EMBOSS and multiple sequences were aligned using the ClustalW algorithm (www.ebi.ac.uk).

\section{Nucleotide sequence accession numbers}

The nucleotide sequences have been submitted to GenBank with accession numbers AY228165-AY228173.

\section{ACKNOWLEDGMENTS}

We thank S.S. Palazzo for unpublished data and other members of the Stuart laboratory for helpful suggestions. We also thank B. Séraphin for pBS1539 plasmid, E. Wirtz and G. Cross for pLew79 plasmid and T. brucei cell line 29.13, and Najib M. El-Sayed for genomic DNA clones. Sequence data were obtained from The Institute for Genomic Research (http://www.tigr.org) and The 
Sanger Centre (http://www.sanger.ac.uk) Web sites. This work was supported by NIH Grant AI14102 to K.S.

The publication costs of this article were defrayed in part by payment of page charges. This article must therefore be hereby marked "advertisement" in accordance with 18 USC section 1734 solely to indicate this fact.

Received December 9, 2002; accepted January 9, 2003.

\section{REFERENCES}

Allen, T.E., Heidmann, S., Reed, R., Myler, P.J., Göringer, H.U., and Stuart, K.D. 1998. The association of guide RNA binding protein gBP21 with active RNA editing complexes in Trypanosoma brucei. Mol. Cell. Biol. 18: 6014-6022.

Aphasizhev, R., Sbicego, S., Peris, M., Jang, S.H., Aphasizheva, I., Simpson, A.M., Rivlin, A., and Simpson, L. 2002. Trypanosome mitochondrial $3^{\prime}$ terminal uridylyl transferase (TUTase): The key enzyme in U-insertion/deletion RNA editing. Cell 108: 637-648.

Blom, D., van den Berg, M., Breek, C.K.D., Speijer, D., Muijsers, A.O., and Benne, R. 2001. Cloning and characterization of two guide RNA-binding proteins from mitochondria of Crithidia fasciculata: gBP27, a novel protein, and gBP29, the orthologue of Trypanosoma brucei gBP21. Nucleic Acids Res. 29: 2950-2962.

Clayton, C., Adams, M., Almeida, R., Baltz, T., Barrett, M., Bastien, P., Belli, S., Beverley, S., Biteau, N., Blackwell, J.M., et al. 1998. Genetic nomenclature for Trypanosoma and Leishmania. Mol. Biochem. Parasitol. 97: 221-224.

Corell, R.A., Read, L.K., Riley, G.R., Nellissery, J.K., Allen, T., Kable, M.L., Wachal, M.D., Seiwert, S., Myler, P.J., and Stuart, K.D. 1996. Complexes from Trypanosoma brucei that exhibit deletion editing and other editing-associated properties. Mol. Cell. Biol. 16: 14101418.

Cruz-Reyes, J., Zhelonkina, A.G., Huang, C.E., and Sollner-Webb, B. 2002. Distinct functions of two RNA ligases in active Trypanosoma brucei RNA editing complexes. Mol. Cell. Biol. 22: 4652-4660.

Drozdz, M., Palazzo, S.S., Salavati, R., O'Rear, J., Clayton, C., and Stuart K. 2002. TbMP81 is required for RNA editing in Trypanosoma brucei. EMBO J. 21: 1791-1799.

Estevez, A.M. and Simpson, L. 1999. Uridine insertion/deletion RNA editing in trypanosome mitochondria: A review. Gene 240: 247260.

Harris, M.E., Moore, D.R., and Hajduk, S.L. 1990. Addition of uridines to edited RNAs in trypanosome mitochondria occurs independently of transcription. J. Biol. Chem. 265: 11368-11376.

Hayman, M.L. and Read, L.K. 1999. Trypanosoma brucei RBP16 is a mitochondrial Y-box family protein with guide RNA binding activity. J. Biol. Chem. 274: 12067-12074.

Huang, C.E., O'Hearn, S.F., and Sollner-Webb, B. 2002. Assembly and function of the RNA editing complex in Trypanosoma brucei requires band III protein. Mol. Cell. Biol. 22: 3194-3203.

Kable, M.L., Heidmann, S., and Stuart, K. 1997. RNA editing: Getting U into RNA. Trends Biochem. Sci. 22: 162-166.

Koller, J., Muller, U., Schmid, B., Missel, A., Kruft, V., Stuart, K., and Göringer, H.U. 1997. Trypanosoma brucei gBP21: An arginine rich mitochondrial protein that binds to guide RNA with high affinity. J. Biol. Chem. 272: 3749-3757.

Madison-Antenucci, S. and Hajduk, S. 2001. RNA editing-associated protein 1 is an RNA binding protein with specificity for preedited mRNA. Mol. Cell 7: 879-886.

Madison-Antenucci, S., Sabatini, R.S., Pollard, V.W., and Hajduk, S.L. 1998. Kinetoplastid RNA-editing-associated protein 1 (REAP-1): A novel editing complex protein with repetitive domains. EMBO J. 17: 6368-6376.

Madison-Antenucci, S., Grams, J., and Hajduk, S.L. 2002. Editing machines: The complexities of trypanosome RNA editing. Cell 108: $435-438$

McManus, M.T., Shimamura, M., Grams, J., and Hajduk, S.L. 2001. Identification of candidate mitochondrial RNA editing ligases from Trypanosoma brucei. RNA 7: 167-175.

Mian, I.S. 1997. Comparative sequence analysis of ribonucleases HII, III, II, PH and D. Nucleic Acids Res. 25: 3187-3195.

Missel, A., Souza, A.E., Norskau, G., and Göringer, H.U. 1997. Disruption of a gene encoding a novel mitochondrial DEAD-box protein in Trypanosoma brucei affects edited mRNAs. Mol. Cell. Biol. 17: 4895-4903.

Muller, U.F., Lambert, L., and Göringer, H.U. 2001. Annealing of RNA editing substrates facilitated by guide RNA-binding protein gBP21. EMBO J. 20: 1394-1404.

Panigrahi, A.K., Gygi, S., Ernst, N., Igo Jr., R.P., Palazzo, S.S., Schnaufer, A., Weston, D., Carmean, N., Salavati, R., Aebersold, R., et al. 2001a. Association of two novel proteins, TbMP52 and TbMP48, with the Trypanosoma brucei RNA Editing Complex. Mol. Cell. Biol. 21: 380-389.

Panigrahi, A.K., Schnaufer, A., Carmean, N., Igo Jr., R.P., Gygi, S., Ernst, N., Palazzo, S.S., Weston, D., Aebersold, R., Salavati, R., et al. 2001b. Four related proteins of the T. brucei RNA editing complex. Mol. Cell. Biol. 21: 6833-6840.

Piller, K.J., Decker, C.J., Rusché, L.N., and Sollner-Webb, B. 1995. Trypanosoma brucei mitochondrial guide RNA-mRNA chimeraforming activity cofractionates with an editing-domain-specific endonuclease and RNA ligase and is mimicked by heterologous nuclease and RNA ligase. Mol. Cell. Biol. 15: 2925-2932.

Pollard, V.W., Harris, M.E., and Hajduk, S.L. 1992. Native mRNA editing complexes from Trypanosoma brucei mitochondria. EMBO J. 11: 4429-4438.

Rigaut, G., Shevchenko, A., Rutz, B., Wilm, M., Mann, M., and Seraphin, B. 1999. A generic protein purification method for protein complex characterization and proteome exploration. Nat. Biotechnol. 17: 1030-1032.

Rusché, L.N., Cruz-Reyes, J., Piller, K.J., and Sollner-Webb, B. 1997. Purification of a functional enzymatic editing complex from Trypanosoma brucei mitochondria. EMBO J. 16: 4069-4081.

Rusché, L.N., Huang, C.E., Piller, K.J., Hemann, M., Wirtz, E., and Sollner-Webb, B. 2001. The two RNA ligases of the Trypanosoma brucei RNA editing complex: Cloning the essential Band IV gene and identifying the Band V gene. Mol. Cell. Biol. 21: 979-989.

Sabatini, R. and Hajduk, S.L. 1995. RNA ligase and its involvement in guide RNA/mRNA chimera formation. Evidence for a cleavageligation mechanism of Trypanosoma brucei mRNA editing. J. Biol. Chem. 270: 7233-7240.

Schnaufer, A., Panigrahi, A.K., Panicucci, B., Igo Jr., R.P., Salavati, R., and Stuart, K.D. 2001. An RNA ligase essential for RNA editing and survival of the bloodstream form of Trypanosoma brucei. Science 291: 2159-2162.

Schnaufer, A., Domingo, G.J., and Stuart, K.D. 2002. Natural and induced dyskinetoplastid trypanosomatids: How to live without mitochondrial DNA. Int. J. Parasitol. 32: 1071-1084.

Seiwert, S.D., Heidmann, S., and Stuart, K. 1996. Direct visualization of uridylate deletion in vitro suggests a mechanism for kinetoplastid RNA editing. Cell 84: 831-841.

Stuart, K. and Panigrahi, A.K. 2002. RNA editing: Complexity and complications. Mol. Microbiol. 45: 591-596.

Stuart, K., Panigrahi, A.K. and Salavati, R., 2000. RNA editing in kinetoplastid mitochondria. In RNA editing: Frontiers in molecular biology (ed. B.L. Bass), pp. 1-19. Oxford University Press, Oxford, UK.

Vanhamme, L., Perez-Morga, D., Marchal, C., Speijer, D., Lambert, L., Geuskens, M., Alexandre, S., Ismaïli, N., Göringer, U., Benne, R., et al. 1998. Trypanosoma brucei TBRGG1, a mitochondrial oligo(u)-binding protein that co-localizes with an in vitro RNA editing activity. J. Biol. Chem. 273: 21825-21833. 

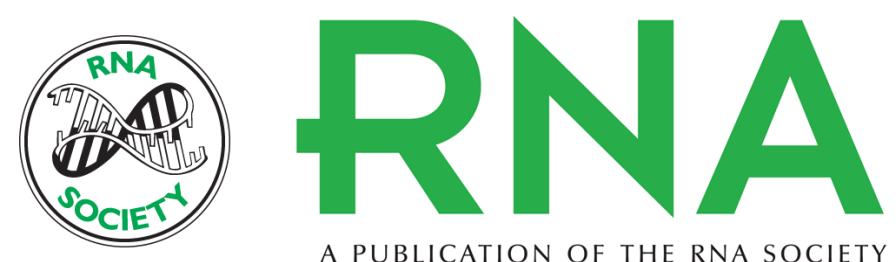

A PUBLICATION OF THE RNA SOCIETY

\section{Identification of novel components of Trypanosoma brucei editosomes}

ASWINI K. PANIGRAHI, ACHIM SCHNAUFER, NANCY L. ERNST, et al.

RNA 2003 9: 484-492

References This article cites 33 articles, 19 of which can be accessed free at: http://rnajournal.cshlp.org/content/9/4/484.full.html\#ref-list-1

\section{License}

Email Alerting Receive free email alerts when new articles cite this article - sign up in the box at the Service top right corner of the article or click here.

To subscribe to RNA go to:

http://rnajournal.cshlp.org/subscriptions 